\title{
Why the xanthine derivatives are used to study of P-glycoprotein- mediated multidrug resistance in L1210/VCR line cells
}

\author{
Peter Dočolomanský, Viera Boháčová, Miroslav Barančík and Albert Breier \\ Institute of Molecular Physiology and Genetics, Slovak Academy of Sciences, Vlárska 5, 833 34 Bratislava, Slovakia
}

\begin{abstract}
There is generally well known that various xanthines occur frequently in natural products, e.g. black coffee, black tea, green tea, natural dyes etc. Xanthine molecules are good tolerated and metabolised by organisms. Moreover, natural xanthines and/or sythesized xanthines may recall a lot positive affects (hemorheologic properties, anti-inflammatory properties, tracheal smooth muscle relaxant, positive chronotropic and central nervous system-stimulating, etc.) and may even induce a quantity of changes on the molecular level (inhibition of cyclic nucleotide phosphodiesterases, inhibition of the synthesis of tumor necrosis factor (TNF- $\alpha$ ), cellular $\mathrm{Ca}^{2+}$ homeostasis, etc.). In our previous paper we showed that some xanthine derivatives (pentoxifylline and its derivatives) depress P-glycoprotein (P-gp) mediated multidrug resistance of the mouse leukemic cells. Other authors, first of all Sadzuka and co-workers, confirm this usefulness of long side substituted xanthines as biochemical modulators. However, the mechanism of molecular action of xanthine derivatives has not been clarified. One of the possible ways to chemosensitize the cancer cells is direct competiting in defence mechanism - inhibition of efflux pump (P-gp). Interaction of xanthine derivatives with binding site of P-gp is a question which could be solved by experiment; although, molecular modelling may clear up this matter. But, each dynamic and static program for molecular simulation of $\mathrm{P}$-gp action is dividing on input variable, considering mechanistic view of insight drug transport.
\end{abstract}

\section{Usefulness of substituted xanthines in reversal of multidrug resistance}

Xanthine (3,7-dihydro-purine-2,6-dione) is a purine base found in most human body tissues and fluids and in other organisms. Substituted xanthines are compounds based on alkylated positions of the purine skeleton at N1, N3, N7 and C8 (Figure 1). Namely: caffeine, theophylline, theobromine, isobutylmethylxanthine (IBMX) and pentoxifylline (PTX), are favourite and often used in various experiments, moreover, they are very good tolerated by organisms.

These alkyl-xanthine derivatives were used in diverse applications, e.g. as: inhibitors of metabolism in sea urchin eggs (Nath and Rebhun 1976), suppressor of cytokineinduced NO production via inhibition of the expression of inducible NO-synthase mRNA in macrophages (Trajkovic et al. 1997), hemorheologic agents (Porter et al.

Correspondence to: Viera Boháčová, Institute of Molecular Physiology and Genetics, Slovak Academy of Sciences, Vlárska 5, 83334 Bratislava

E-mail: viera.bohacova@savba.sk
1982), improvers of circulatory failure in murine models of endotoxaemia (Wu et al. 1999), anti-inflammatory agents (Rao et al. 2005), nonspecific inhibitors of cyclic nucleotide phosphodiesterases (Nicholson et al. 1991). Moreover, alkyl-xanthine derivatives constitute nonspecific phosphodiesterase inactivators - they increase the cyclic adenosine monophosphate (cAMP) level in the cells thus inhibiting the synthesis not only of TNF- $\alpha$, but also of IL-1L, IL-6, and IL-8 (Han et al. 1990; Semmler et al. 1993; Zabel et al. 1993; Neuner et al. 1994). However, other authors describe that xanthines have long been known for their effects on cellular $\mathrm{Ca}^{2+}$ homeostasis (Huddart and Syson 1975; Peterson et al. 1979; Deth et al. 1981; Jiang et al. 1984).

Xanthine derivatives have some pharmacological actions such as tracheal smooth muscle relaxant, positive chronotropic and central nervous system-stimulating ones, which widely varied with the xanthine skeleton substituents (Takagi et al. 1988; Miyamoto et al. 1989, 1992, 1993, 1995; Sakai et al. 1992; Sanae et al. 1995). Sadzuka and co-workers (1993, 1995, 1998, 1999, 2000, 2002, 2004) tested xanthine derivatives based on 1,7-alkylated-3-n-propyl xanthine skeleton as 


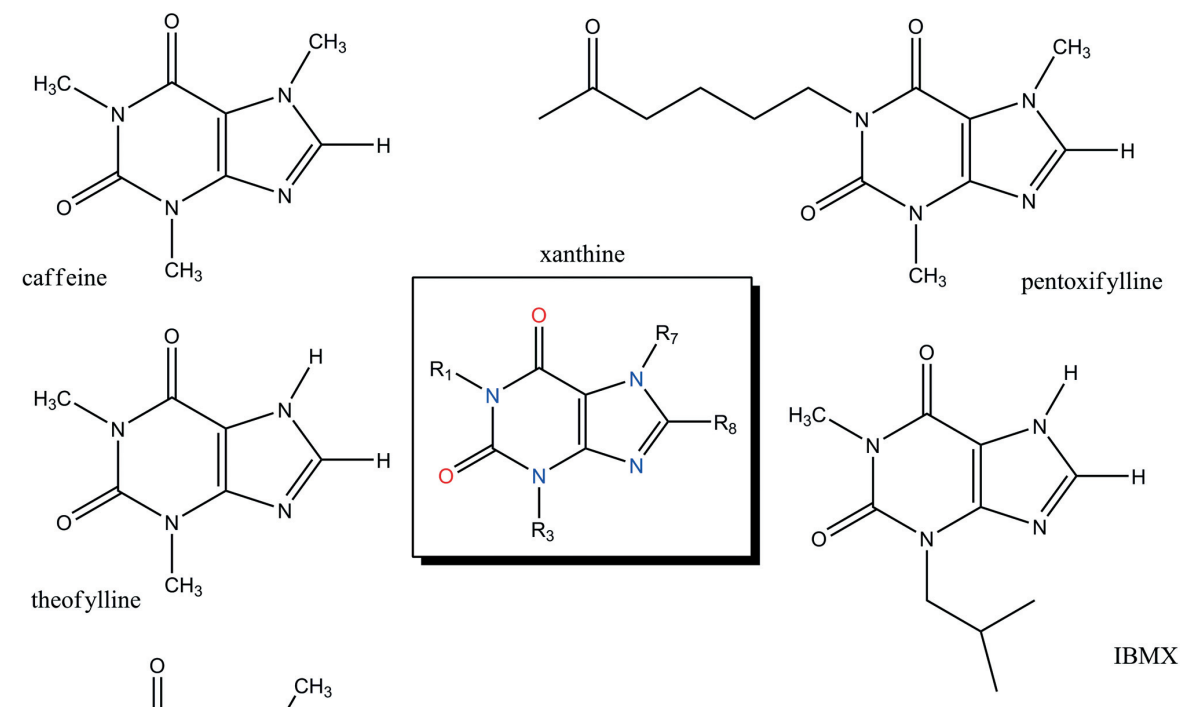<smiles>[2H]c1nc2c(c(=O)[nH]c(=O)n2C)n1C</smiles><smiles>C=CCCCCCCCCCN1C(=C)Cc2nc(N)n(C)c2C1=O</smiles>

theobromine<smiles>CCn1c(=O)c2c(nc(NC3CCCC3O)n2Cc2ccc(OC)c(Br)c2)n(CCO)c1=O</smiles><smiles>CCCCCCCN(C=O)CNC</smiles>

MTT analogue

Figure 1. Xanthine skeleton (in the middle) and selected derivatives - substituted position R1, R3, R7 and R8. PTX-UHM, 1-undecylenyl3-heptyl-7-methyl xanthine - compound with aliphatic carbohydrate chains; MTT analogue, 1-ethyl-3-(2-hydroxyethyl)-7-(2-bromo4-methoxy-benzyl)-8-(2-hydroxy-cyclopenthylamino) xanthine - compound with non-aliphatic substituents.

biochemical modulators of DOX at P388 (leukaemic) and P388/DOX (resistance) cells, but the mechanism of action of these xanthine derivatives have not been clarified. Radiosensitization of lung carcinoma cells by IBMX were compared with other alkyl-xanthines (Malki et al. 2006). IBMX was more potent than the derivatives without 3-isobutyl substituent (Figure 1) in radiosensitization of normal lung epithelial cells and the lung carcinoma cells stably transfected with wild-type p53. IBMX increased p53 protein level more than caffeine in lung carcinoma cells stably transfected with wildtype $\mathrm{p} 53$. This suggests that 3-isobutyl-methylxanthine might function through a p53-dependent mechanism.
It is worth noticing that the ability of xanthine derivatives with long carbohydrate sidechain on N1 or/and N3 (e.g. PTX, PTX-UHM, Figure 1) to interfere in multidrug resistance (MDR) is not common for all tested xanthine derivatives (Dočolomanský et al. 2005) and could not be explained on the basis of known biological activities of substituted xanthines (such as inhibition of phosphodiesterase activity, inhibition of TNF- $\alpha$ synthesis, activation of calcium-induced calcium repase channels, etc.). MDR is a phenomenon when cancer cells became resistant to wide range of structurally and functionally various unrelated anticancer agents (Ling 1997). The MDR phenotype is observed in rodent and human 
H-bond donor (P-gp)

Abundance

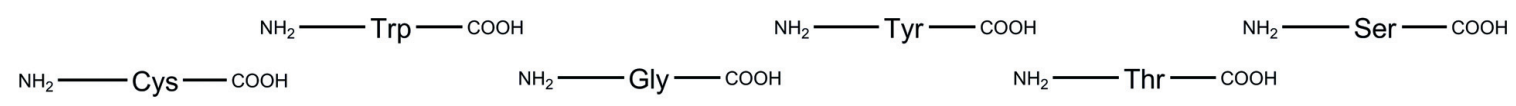

Basic H-bond in xanthine
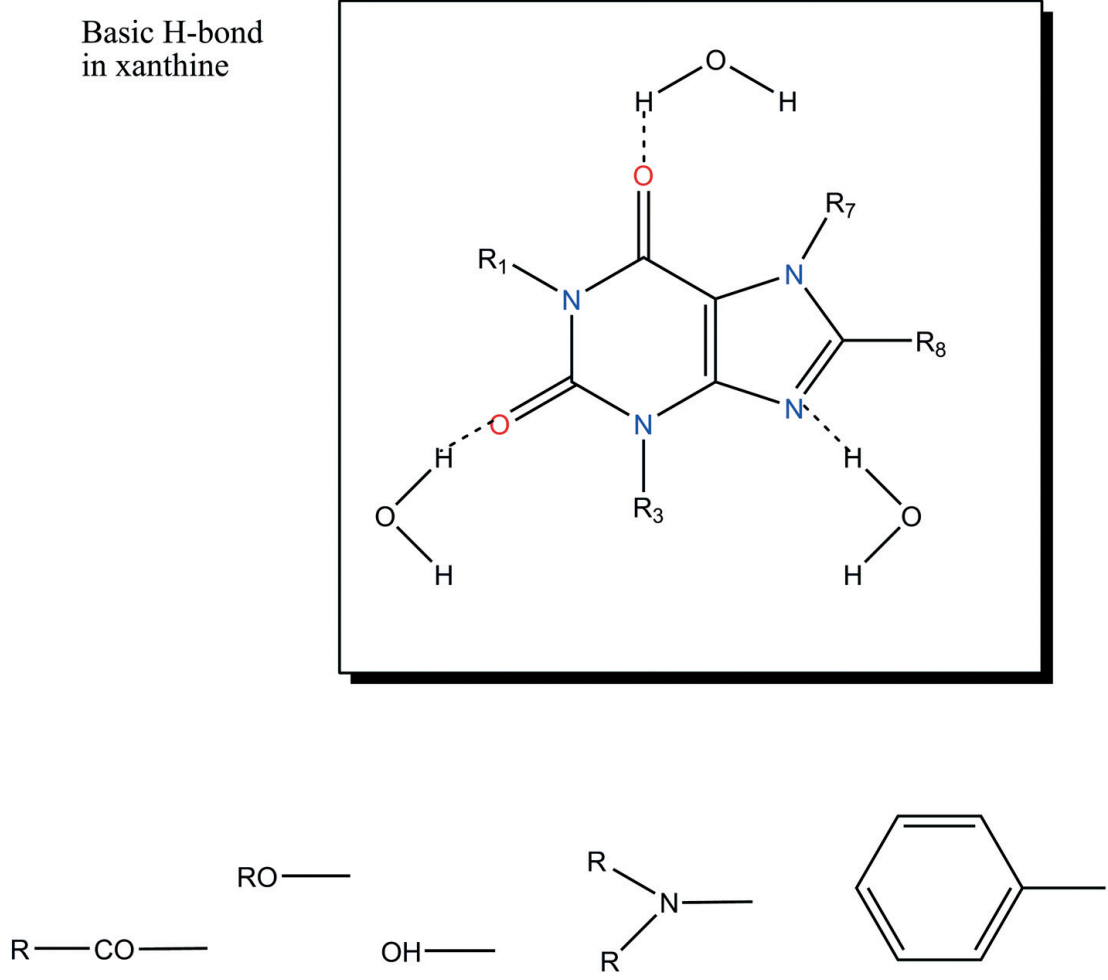

$\mathrm{F}$

H-bond acceptor (agent)

Hydrogen bond energy

Figure 2. H-bond groups in substituted xanthine. Upper line: donor groups found in transmembrane amino acid sequences of P-gp in order of abundance. Lower line: acceptor groups in order of H-bond strength, in the middle is structure of possible H-bond in xanthine skeleton.

cell lines selected for resistance to a single anticancer drug (Litiman et al. 2001). This type of resistance is often caused by activity of drug efflux of ATP-dependent pump, called P-glycoprotein (P-gp, product of $m d r 1$ and $m d r 3$ genes). P-gp is an integral membrane protein $(170 \mathrm{kDa})$ located in the cell plasma membrane and exports structurally diverse groups of substances out of cytoplasm (Kvačkajová-Kišucká et al. 2001; Wiese et al. 2001). However, the mechanism of MDR depression through partial or full suppression of P-gp transport activity by agents called chemosensitizers is not clear (Breier et al. 2005). Most chemosensitizers bind with transmembrane domain in P-gp, but steroids and flavonoids are new recently introduced chemosensitizers, which inhibit these transport proteins by binding with nucleotide-binding domain (Dayan et al. 1997; Consell et al. 1998).

\section{Structure-activity relationship between substituted xanthines and target transporter}

Structure-activity relationship studies attempt to identify complementary spatial features in ligand-receptor or xanthines-transporter interaction. The pharmacophore is defined as critical functional group in the ligand that is 


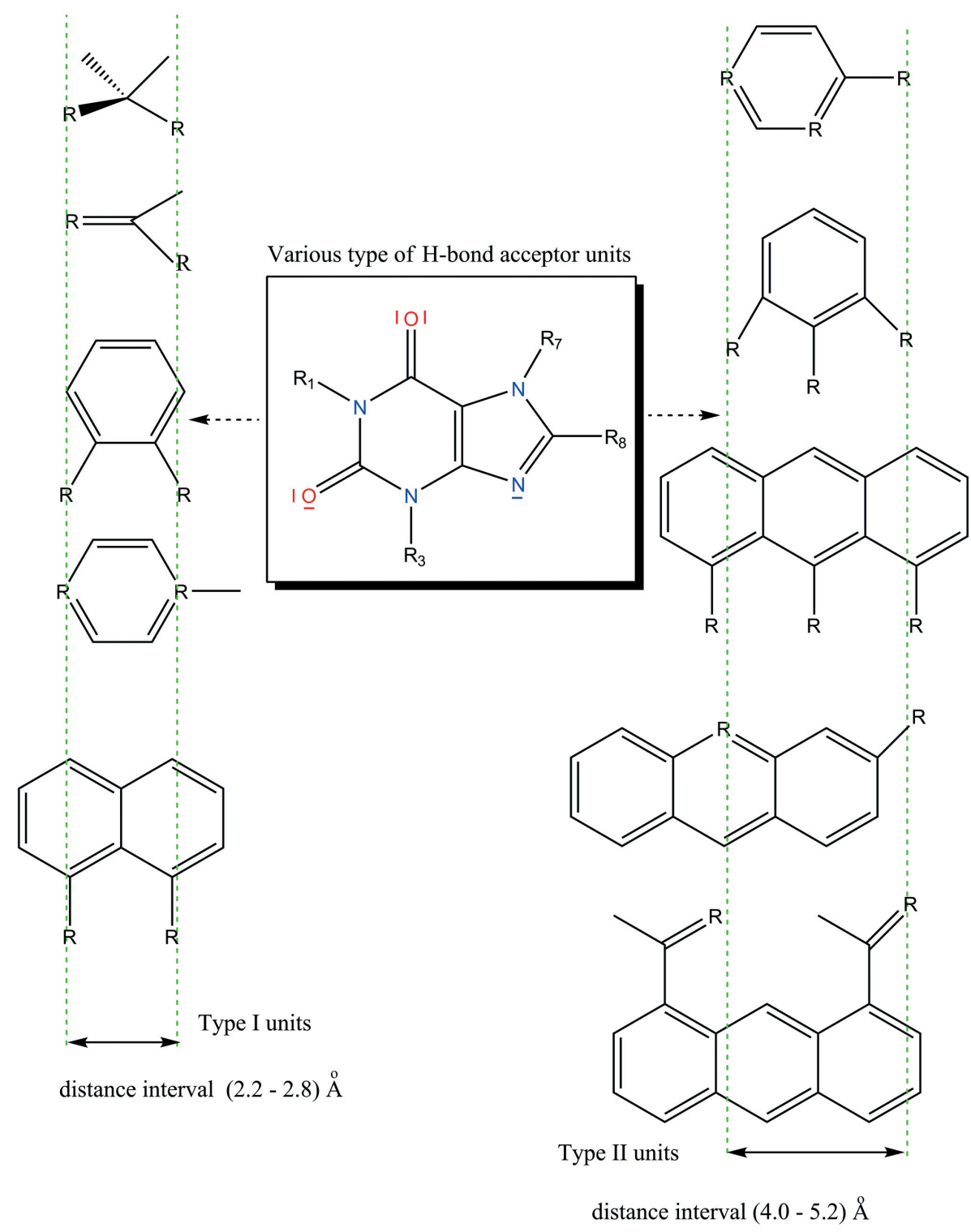

Figure 3. H-bond acceptor patterns observed in P-gp substrates. In the middle: substituted xanthine skeleton with possible free electron pairs could satisfy type I or type II. Type I $(2.5 \pm 0.3 \AA)$, two electron donor units; type II ( $4.6 \pm 0.6 \AA$, outer groups), three electron donor units; $\mathrm{R}$, heteroatoms or substituents.

responsible for creating biological response (Stouch et al. 2002). A lot of information on substrate and P-gp interactions has been gathered in the late 1970's and they are based on multiple linear regression using a variable number of descriptors, e.g. lipophilicity (Penzotti et al. 2002), H-bond ability (Klopman et al. 1997; Ecker et al. 1999), molecular weight, size, and surface area (Eytan et al. 1999; Lentz et al. 2000; Kupsáková et al. 2004), unsaturated rings (Zamora et al. 1988), etc.

Various attempts have been made to find a common set of structural features required for substrate to interact with
P-gp. First, some experiments suggested the requirement of a basic nitrogen atom and two planar aromatic domains (Pearce et al. 1989). However, later observation showed that basic nitrogen is not essential. The nitrogen occurs in imines (-N=, pyroles, imidazoles and pyrimidines) and in substituted amines (-NR2) or amides; but, only tertiary and quaternary amines and $\mathrm{N}$-methyl amides seem to be involved in an interaction with P-gp. The second, cluster of electron donor groups ( $\mathrm{H}$-bond acceptors) were observed in compounds, which are known to be substrates or modulators of P-gp (e.g. electronegative atoms $\mathrm{O}, \mathrm{N}, \mathrm{S}$, or $\mathrm{F}, \mathrm{Cl}$; 
unshared electron pair; or unsaturated system with a $\pi$ electron orbital) (Seelig et al. 2003) (Figure 2). The third, spatial distances among various electron donors (Seeleig 1998; Pajeva et al. 2002; Penzotti et al. 2002; Globisch et al. 2006) are resulted into two types of pattern. The type I units are formed by two $\mathrm{H}$-bond acceptor groups with a spatial separation $2.5 \pm 0.3 \AA$. Type II units are formed either by three $\mathrm{H}$-bond acceptor groups separated from each other by $2.5 \pm 0.3 \AA$, with a spatial separation of the outer two acceptor groups of $4.6 \pm 0.6 \AA$; or by only two H-bond acceptor groups with a spatial separation $4.6 \pm 0.6 \AA$ (Figure 3). Calculated spatial distances among electron donor groups in the selected xanthine derivatives homologate them to the type of a pattern I unit and II unit (Dočolomanský et al. 2009). Recently, a $2.5 \mathrm{~nm}$ resolution structure of P-gp was obtained by electron microscopy and single-particle image analysis (Rosenberg et al. 1997). In the P-gp molecule there is a large central pore, $\sim 5 \mathrm{~nm}$ in diameter, which is closed at the inner (cytoplasmic) side of the plasma membrane (Bosch and Croop 1996). The aim of research is to reveal the putative role of the interaction of some chemosensitizers with the lipid phase in the mechanism of drug resistance reversal caused by these compounds. The interactions of MDR modulators with phospholipid liposomes and multilamellar lipid structures were studied using fluorescence spectroscopy, absorption spectroscopy and differential scanning microcalorimetry (Ford et al. 1989).

The interactions of transported drugs with the lipid bilayer and P-gp through a solvation exchange mechanism (Omote and Al-Shawi 2006) were postulated by molecular dynamic (MD) simulation and drug transport was illustrated in detail. Using MD simulation they predict important parameters (H-bond interaction energies) that are not directly measurable and provide a compelling link between the rate of transport and the $\mathrm{H}$-bonding potential of the substrates. However, this model goes beyond descriptive and provides new mechanistic insight into drug transport (Seelig 2006).

Substituted xanthines by long aliphatic side chain fulfill above constellate molecular model as modulators or chemosensitizers, but mechanism of multidrug resistance influencing is not resolved yet.

Acknowledgement. This study was supported by grants from the Slovak Grant Agency for Science VEGA 2/7124/27 and VEGA 2/0169/10.

\section{References}

Bosch I., Croop J. (1996): P-glycoprotein multidrug resistance and cancer. Biochim. Biophys. Acta 1288, F37-54

Breier A., Barančik M., Sulová Z., Uhrik B. (2005): P-glycoprotein - implications of metabolism of neoplastic cells and cancer therapy. Curr. Cancer Drug Targets 5, 457-468; doi:10.2174/1568009054863636

Consell G., Baubichon-Cortay H., Dayan G., Jault J. M., Barron D., DiPietro A. (1998): Flavonoids: a class of modulators with bifunctional interactions at vicinal ATP- and steroid-binding sites on mouse P-glycoprotein. Proc. Natl. Acad. Sci. U.S.A. 95, 9831-9836; doi:10.1073/ pnas.95.17.9831

Dayan G., Jault J. M., Baubichon-Cortay H., Baggetto L. G., Renoir J. M., Baulieu E. E., Gros P., DiPietro A. (1997): Binding of steroid modulators to recombinant cytosolic domain from mouse P-glycoprotein in close proximity to the ATP site. Biochemistry 36, 15208-15215; doi:10.1021/bi9718696

Deth R. C., Lynch C. J. (1981): Mobilization of a common source of smooth muscle $\mathrm{Ca} 2+$ by norepinephrine and methylxanthines. Am. J. Physiol. 240, C239-247

Dočolomanský P., Fialová I., Barančík M., Rybár A., Breier A. (2005): Prolongation of Pentoxifylline aliphatic side chain positively affects the reversal of P-glycoprotein-mediated multidrug resistance in L1210/VCR line cells. Gen. Physiol. Biophys. 24, 461-466

Dočolomanský P., Boháčová V., Barančík M. (2009): Structural features determining the efficiency of pentoxifylline derivatives in reversal of P-gp mediated resistance in L1210/VCR cells. 85. Physiological days, Prague

Ecker G., Huber M., Schmid D., Chiba P. (1999): The importance of a Nitrogen atom in modulators of multidrug resistance. Mol. Pharmacol. 56, 791-796

Eytan G. D., Kuchel P. W. (1999): Mechanism of action of P-glycoprotein in relation to passive membrane permeatio. Int. Rev. Cytol. 190, 175-250; doi:10.1016/S00747696(08)62148-8

Ford J. M., Prozialeck W. C., Hait W. N. (1989): Structural features determining activity of phenothiazines and related drugs for inhibition of cell growth and reversal of multidrug resistance. Mol. Pharmacol. 35, 105-115

Globisch Ch., Pajeva I. K., Wiese M., (2006): Structure-activity relationships of a series of tariquidar analogs as multidrug resistance modulators. Bioorg. Med. Chem. 14, 1588-1598; doi:10.1016/j.bmc.2005.10.058

Han J., Thompson P., Beutler B. (1990): Dexamethasone and pentoxifylline inhibit endotoxin-induced cachectin/tumor necrosis factor synthesis at separate points in the signaling pathway. J. Exp. Med. 172, 391-394; doi:10.1084/ jem.172.1.391

Huddart H., Syson A. J. (1975): The effect of caffeine on calcium efflux and calcium translocation in skeletal an visceral muscle. J. Exp. Biol. 63, 131-142

Jiang C. S., Kilfeather S. A., Pearson R. M., and Turner P. (1984): The stimulatory effects of caffeine, theophylline, lysinetheophylline and 3-isobutyl-1-methylxanthine on human sperm motility. Br. J. Clin. Pharmacol. 18, 258-262

Klopman G., Shi L. M., Ramu A. (1997): Quantitative-structure activity relationship of multidrug resistance reversal agents. Mol. Pharmacol. 52, 323-334

Kupsáková I., Rybár A., Dočolomanský P., Drobná Z., Stein U., Walther W., Barančík M., Breier A., (2004): Reversal 
of P-glycoprotein mediated vincristine resistance of L1210/VCR cells by analogues of pentoxifylline. A QSAR study. Eur. J. Pharm. Sci. 21, 283-293; doi:10.1016/ j.ejps.2003.10.019

Kvačkajová-Kišucká J., Barančík M., Breier A. (2001): Drug transporters and their role in multidrug resistance of neoplastic cells. Gen. Physiol. Biophys. 20, 215-237

Lentz K. A., Polii J. W., Wring S. A., Humphreys J. E., Polli J. E. (2000): Influence of passive permeability on apparent P-glycoprotein kinetics. Pharm. Res. 17, 1456-1460; doi:10.1023/A:1007692622216

Ling V. (1997): Multidrug resistence: molecular mechanisms and clinical relevance. Cancer. Chemother. Pharmacol. 40 (Suppl.), S3-8; doi:10.1007/s002800051053

Litiman T., Druley T. E., Stein W. D., Bates S. E. (2001): From MDR to MXR: new understanding of multidrug resistance systems, their properties and clinical significance. Cell. Mol. Life Sci. 58, 931-959; doi:10.1007/PL00000912

Malki A. M., Gentry J., Evans S. C. (2006): Differential effect of selected methylxanthine derivatives on radiosensitization of lung carcinoma cells. Exp. Oncol. 28, 16-24

Miyamoto K., Takagi K., Sakai R., Wakusawa S., Koshiura R., Nadai M., Apichartpichean R., Hasegawa T. (1989): Correlation between hydrophobicity of $\mathrm{N}$-alkylxanthine derivatives and their biological activities on guineapig isolated tracheal smooth muscle. J. Pharm. Pharmacol. 41, 844-847

Miyamoto K., Sakai R., Yamamoto Y., Konno K., Sanae F., Hasegawa T., Takagi K. (1992): Selective bronchodilators from 1-(5oxohexyl)xanthines. J. Pharm. Pharmacol. 44, 888-892

Miyamoto K., Yamamoto Y., Kurita M., Sakai R., Konno K., Sanae F., Ohshima T., Takagi K., Hasegawa T., Iwasaki N., Kakiuchi N., Kato H. (1993): Bronchodilator activity of xanthine derivatives substituted with functional groups at the 1- or 7-position. J. Med. Chem. 36, 1380-1386; doi:10.1021/jm00062a010

Miyamoto K., Sakai R., Kurita M., Ohmae S., Sanae F., Sawanishi H., Hasegawa T., Takagi K. (1995): Effects of alkyl substituents of xanthine on phosphodiesterase isoenzymes. Biol. Pharm. Bull. 18, 431-434

Nath J., Rebhun L. I. (1976): Effects of caffeine and other methylxanthines on development and metabolism of sea urchin eggs. J. Cell. Biol. 68, 440-450; doi:10.1083/jcb.68.3.440

Neuner P., Klosner G., Schauer E. (1994): Pentoxifylline in vivo down-regulates the release of IL-1 beta, IL-6, IL-8 and tumour necrosis factor-alpha by human peripheral blood mononuclear cells. Immunology 83, 62-67

Nicholson C. D., Challis R. A. J., Shahid M. (1991):. Differential modulation of tissue function and therapeutic potential of selective inhibitors of cyclic nucleotide phosphodiesterase isoenzymes. Trends Pharmacol. Sci. 12, 19-27; doi:10.1016/0165-6147(91)90484-A

Omote H., Al-Shawi M. K. (2006): Interaction of transported drugs with the lipid bilayer and P-glycoprotein through a solvation exchange mechanism. Biophys. J. 80, 4046-4059; doi:10.1529/biophysj.105.077743

Pajeva I. K., Wiese M. (2002): Pharmacophore model of drugs involved in P-glycoprotein multidrug resistance: explana- tion of structural variety (Hypothesis). J. Med. Chem. 45, 5671-5686; doi:10.1021/jm020941h

Penzotti J. E., Lamb M. L., Evensen E., Grootenhuis P. D. (2002): A computational ensemble pharmacophore model for identifying substrates of P-glycoprotein. J. Med. Chem. 45, 1737-1740; doi:10.1021/jm0255062

Pearce H. L., Safa A. R., Bach N. J., Winter M. A., Cirtain M. C., Beck W. T. (1989): Essential features of the P-glycoprotein pharmacophore as defined by a series of reserpine analogs that modulate multidrug resistance. Proc. Natl. Acad. Sci. 86, 5128-5132; doi:10.1073/pnas.86.13.5128

Peterson R. N., Seyler D., Bundman D., Freund M. (1979): The effect of theophylline and dibutyryl cyclic AMP on the uptake of radioactive calcium and phosphate ions by boar and human spermatozoa. J. Reprod. Fertil. 55, 385-390; doi:10.1530/jrf.0.0550385

Porter J. M., Cutler B. C., Lee B. Y. (1982): Pentoxifylline eficacy in the treatment on intermittent claudication:multicenter controlled double-blind trial with objective assessment of chronic occlusive arterial dinase patiens. Am. Heart J. 104, 66-72; doi:10.1016/0002-8703(82)90642-1

Rao F. V., Andersen O. A., Vora K. A., DeMartino J. A., van Aalten D. M. F. (2005): Methylxanthine drugs are Chitinase inhibitors: investigation of inhibition and binding modes. Chem. Biol. 12, 973-980; doi:10.1016/j.chembiol.2005.07.009

Rosenberg M. F., Callaghan R., Ford R. C., Higgins C. F. (1997): Structure of the multidrug resistance P-glycoprotein to $2.5 \mathrm{~nm}$ resolution determined by electron microscopy and image analysis. J. Biol. Chem. 272, 10685-10694; doi:10.1074/jbc.272.16.10685

Sakai R., Konno K., Yamamoto Y., Sanae F., Takagi K., Hasegawa T., Iwasaki N., Kakiuchi M., Kato H., Miyamoto K. (1992): Effects of alkyl substitutions of xanthine skeleton on bronchodilation. J. Med. Chem. 35, 4039-4044; doi:10.1021/jm00100a008

Sadzuka Y., Mochizuki E., Takino Y. (1993): Caffeine modulates the antitumor activity and toxic side effects of adriamycin. Jpn. J. Cancer Res. 84, 348-353

Sadzuka Y., Mochizuki E., Iwazaki A., Hirota S., Takino, Y. (1995): Caffeine enhances adriamycin antitumor activity in Ehrlich ascites carcinoma-bearing mice. Biol. Pharm. Bull. 18, 159-161

Sadzuka Y., Iwazaki A., Sugiyama T., Sawanishi H., Miyamoto K. (1998): 1-Methyl-3-propyl-7-butylxanthine, a novel biochemical modulator, enhances therapeutic efficacy of adriamycin. Jpn. J. Cancer Res. 89, 228-233

Sadzuka Y., Sugiyama T., Sawanishi H., Miyamoto K. (1999): Enhanced efficacy of 1-methyl-3-propyl-7-butylxanthine on the antitumor activity of doxorubicin against doxorubicin-resistant P388 leukemia. Cancer Lett. 138, 5-11; doi:10.1016/S0304-3835(98)00375-9

Sadzuka Y., Egawa Y., Sugiyama T., Sawanishi H., Miyamoto K., Sonobe T. (2000): Effects of 1-methyl-3-propyl-7-butylxanthine (MPBX) on idarubicin-induced antitumor activity and bone marrow suppression. Jpn. J. Cancer Res. 91, 651-657

Sadzuka Y., Egawa Y., Sawanishi H., Miyamoto K., Sonobe T. (2002): Effects of xanthine derivatives on the influx and efflux of 
doxorubicin in P388 and DOX-resistant P388 leukemia cells. Toxicol. Lett. 135, 137-144; doi:10.1016/S03784274(02)00227-8

Sadzuka Y., Sugiyama T., Suzuki H., Sawanishi H., Miyamoto K. (2004): Increased effects of MPDAX, a novel xanthine derivative, on antitumor activity of doxorubicin. Toxicol. Lett. 150, 341-34; doi:10.1016/j.toxlet.2004.02.005

Sanae F., Ohmae S., Kurita M., Sawanishi H., Takagi K., Miyamoto K. (1995): Structure-activity relationships of alkylxanthines: alkyl chain elongation at the N1 or N7-position decreases cardiotopic activity in the isolated guineapig heart. Jpn. J. Pharmacol. 69, 75-82; doi:10.1254/jjp.69.75

Seelig A. (1998): How does P-glycoprotein recognize its substrates? Int. J. Clin. Pharm. Therap. 36, 50-54

Seelig A., Gatlik E., Fischer H., Li-Blatter X. (2003): Towards Pglycoprotein structure-activity relationship. In: Drug Bioavailability/Estimation of Solubility, Permeability, and Absorption. (Eds. van de Waterbeemd and A. Lennernäs), pp. 461-492, Wiley/VCH, Weinheim

Seelig A. (2006): Unraveling membrane-mediated substrate-transporter interaction. Biophys. J. 90, 3825-3826; doi:10.1529/ biophysj. 106.082008

Semmler J., Gebert U., Eisenhut T. (1993): Xanthine derivatives: comparison between suppression of tumour necrosis factoralpha production and inhibition of cAMP phosphodiesterase activity. Immunology 78, 520-525
Stouch T. R., Gudmundsson O. (2002): Progress in understanding the structure-activity relationship of P-glycoprotein. Adv. Drug Deliv. Rev. 54, 315-328; doi:10.1016/S0169409X(02)00006-6

Takagi K., Hasegawa T., Kuzuya T., Ogawa K., Watanabe T., Satake T., Miyamoto M., Wakusawa S., Koshiura R. (1988): Structure-activity relationship in N3-alkylxanthine derivatives. Jpn. J. Pharmacol. 46, 373-378; doi:10.1254/jjp.46.373

Trajkovic V., Bodovinac V., Popadic D., Hadzic O., Stojkovic M. M. (1997): Cell-specific effects of pentoxifylline on nitric oxide production and inducible nitric oxide synthase mRNA expression. J. Immunol. 92, 402-406; doi:10.1046/j.13652567.1997.00354.x

Wiese M., Pajeva I. K. (2001): Structure-activity relationship of multidrug resistance reversers. Curr. Med. Chem. 8, 685-713

Zabel P., Schade F. U., Schlaak M. (1993): Inhibition of endogenous TNF formation by pentoxifylline. Immunobiology 187 , 447- 463

Zamora J. M., Pearce H. L., Beck W. T. (1988): Physical-chemical properties shared by compounds that modulate multidrug resistance in human leukemic cells. Mol. Pharmacol. 33, $454-462$

Received: January 19, 2010

Final version accepted: March 18, 2010 